\title{
Genetic control of fission yeast cell wall synthesis: the genes involved in wall biogenesis and their interactions in Schizosaccharomyces pombe
}

\author{
Junpei Ishiguro \\ Department of Biology, Faculty of Science, Konan University, Okamoto 8-9-1, \\ Higashinada-ku, Kobe 658-8501, Japan
}

\begin{abstract}
The fungal cell wall is an essential structure which protects cells from various environmental stresses such as hyper- or hypo-osmosis, and endows them with specific morphology in response to their life or cell division cycle. In addition, the cell wall has a variety of enzymatic activities per se, which are required for nutritional uptake, secretion, and cell adhesion including mating processes. In addition to these cytological interests, clinical demands to clarify the regulatory mechanisms of cell wall synthesis have been increasing, since the cell wall is a unique and effective target of antifungal agents. However, the molecular mechanisms are poorly understood at present, although the role of several signal transduction pathways have recently been implicated in regulation. In this review, the author focuses on genes and their interactions which are involved in fission yeast cell wall biogenesis.
\end{abstract}

\section{INTRODUCTION}

Fungal cell walls have been studied most extensively in the budding yeast Saccharomyces cerevisiae and their biochemistry, physiology, and molecular genetics have been reviewed (for recent reviews, see Fleet, 1991; Klis, 1994; Cid et al., 1995; Inoue et al., 1996; Orlean, 1997). Our knowledge of the cell wall of the fission yeast Schizosaccharomyces pombe is less complete than that of budding yeast. However, fission yeast have certain advantages over the budding yeast in that the former is much closer to higher eukaryotes than the latter from cytological point of view. This is especially true with respect to the manner of cell division, which is basically similar to higher eukaryotic cells. In fact, fission yeast have long been the subject of extensive investigations of the cell cycle as well as morphogenesis (Nurse, 1994). Thus, fission yeast have the potential to provide us with useful information which cannot be obtained from the budding yeast.

$S$. pombe has cylindrical rod-shaped cell with hemispherical ends. Cell growth is achieved only by tip elongation along the long cell axis which remains constant in diameter. Following mitosis, cytokinesis occurs by division via the newly synthesized septum which is similar to the wall in composition. Accordingly, cell polarity, cell growth, and cell division are largely defined by wall formation. When wall formation takes place normally, the cylindrical cell shape is maintained precisely throughout the cell cycle. S. pombe is thus exceptionally amenable to the study of mechanisms which regulate cell wall synthesis and relationships between wall organization and cell morphogenesis. This review will briefly summarize $S$. pombe wall composition and architecture first and then discuss genes and their interactions which are involved in cell wall biogenesis in detail.

\section{CELL WALL COMPOSITION AND ARCHITECTURE}

Wall composition. The cell wall of $S$. cerevisiae is basically composed of three components, a $\beta$-linked glucan (50 to $60 \%$ of the wall weight), a mannoprotein (25 to $40 \%$ ), and chitin ( 1 to $2 \%)$. The $\beta$-glucans contain mainly $1,3-\beta$ linkages of about 1500 residues as a backbone chain. In addition, a small amount of 1,6- $\beta$-glucans having about 140 residues are also present. Both types of $\beta$-glucans contain some branched residues. The wall composition of $S$. pombe differs to some extent from that of the budding yeast. In addition to $\beta$-glucans ( 46 to $54 \%$ ) which seem to be qualitatively comparable to those of the budding yeast, the $S$. pombe cell wall contains a substantial amount of a linear 1,3- $\alpha$-glucan (18 to $28 \%$ ) and a galactomannnan (9 to 14\%) instead of mannan (Bacon et al., 1968; Bush et al., 1974; Manners et al., 1974; Manners and Meyer, 1977; Horisberger and Rosset, 1977). Chitin is a component that may have some roles in morphogenesis, via the formation of a complex with $\beta$-glucans in several genus of Ascomycetes. However, the presence of this polysaccharide in $S$. pombe cell wall remains controversial (Poole and Lloyd, 1973; 
Bush et al., 1974; Manners and Meyer, 1977; Horisberger et al., 1978). More recently, however, not only a minute amount of glucosamine, a monomeric unit of chitin, but also a chitin synthase activity (Sietsma and Wessels, 1990) and a chitin synthase gene homolog (Bowen et al., 1992) have been detected in $S$. pombe cells.

Wall architecture. Ultrastructural studies have shown that yeast cell walls are layered in appearance. Using immunocytochemical techniques, $\alpha$-galactomannan and $\beta$-glucan were shown to be localized in $S$. pombe cell walls (Horisberger et al., 1978; Horisberger and Rouvet-Vauthey, 1985). The former is present throughout the cell wall, particularly at the periphery of the wall and near the plasma membrane. The latter are also observed throughout the wall, but are more dense in the inner electron-lucent part of the wall as well as the primary septum, as evidenced by staining. Scanning electron microscopy showed that the two types of polysaccharides are exposed in completely different areas on the external surface of the wall: the $\alpha$-galactomannan is present over the entire growing area by extension, while the $\beta$-glucan is present only at the tip area, which is newly generated by fission. Thus, in an established wall area, the $\alpha$-galactomannann overlays the $\beta$-glucan. These polysaccharides are interwoven with each other to a considerable extent. The wall architecture in $S$. pombe appears to be very similar to those observed in $S$. cerevisiae, in which mannoproteins are enriched in the outer electron-dense layer of the wall, as well as at the periphery of the plasma membrane, and $\beta$-glucans are located in a transparent inner layer of the wall. The 1,3$\beta$-glucan is mainly responsible for the mechanical strength of the wall, and probably is present abundantly in the most inner portion of the wall as a fibrillar material. Using $S$. pombe protoplast-regenerating systems, it has been demonstrated that $\beta$-glucan synthesis precedes the formation of $\alpha$-glucan (Kreger and Kopecka, 1978) and that $\beta$-glucans are generated as secreted fine particles, which then develop into a ribbon-shaped fibril network about 16 $\mathrm{nm}$ thick, which covers the entire protoplast surface (Osumi et al., 1989; Osumi et al., 1995).

\section{GENES INVOLVED IN CELL WALL INTEGRITY}

Genes directly related to $\mathbf{1 , 3 - \beta}-\boldsymbol{\beta}$-glucan synthesis. Genes of which mutation, disruption, or overexpression cause cell wall defects have been identified and characterized in S. pombe (see Table 1). Among them, three genes, $c w g 2^{+}, c p s 1^{+}$, and $r h o 1^{+}$are directly involved in the synthesis of 1,3- $\beta$-glucan, a major cell wall component responsible for the wall rigidity. The 1,3- $\beta$-glucan is synthesized from UDP-glucose by $1,3-\beta$-glucan synthase complex located on the plasma membrane. The fungal 1,3- $\beta$-glucan synthase complex consists of at least two components, a membranebound catalytic subunit and a detergent-soluble GTP-bind- ing regulatory subunit. In $S$. cerevisiae, a gene which codes for a $215-\mathrm{kDa}$ integral membrane protein was first isolated as FKS1 (Douglas et al., 1994; Eng et al., 1994), and several different $f k s 1$ alleles which cause altered sensitivities to cell wall inhibitors were also identified (Ram et al., 1995; Castro et al., 1995). The independently isolated genes were proven to code for the catalytic subunit of 1,3- $\beta$-glucan synthase using product entrapment, and are also named GSC1 (Inoue et al., 1995). This yeast has another closely related gene, FKS2 (GSC2), whose product has $88 \%$ amino acid sequence identity with Fks1p (Mazur et al., 1995; Inoue et al., 1995). FKS1 is predominantly expressed during growth on glucose in a cell cycle dependent manner, while $F K S 2$ transcription is induced during growth on poor carbon sources, or by the presence of high extracellular $\mathrm{Ca}^{2+}$ concentrations and mating pheromone. The induction of transcription by $\mathrm{Ca}^{2+}$ or pheromone is completely dependent on the $\mathrm{Ca}^{2+} /$ calmodulin-dependent protein phosphatase calcineurin, the activity of which is highly sensitive to the immunosuppressants, cyclosporin A (CsA) and FK506. When Fks1p activity is lost, Fks2p becomes essential for 1,3- $\beta$-glucan synthesis, vital to survival. Therefore, certain fks1 mutant alleles confer hypersensitivity to the drugs or synthetic lethality with depletion of calcineurin (Garrett-Engele et al., 1995) even under vegetative growth conditions.

In $S$. pombe, the cps1 mutant also displays hypersensitivity to CsA as well as papulacandin B, a potent inhibitor

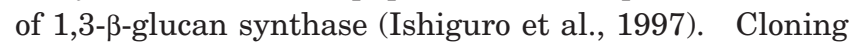
and sequence analysis have shown that the $c p s 1^{+}$gene appears to be a homolog of the FKS genes, with $69 \%$ amino acid sequence identity in the tentative catalytic domain of these products. Although the CsA sensitivity is very similar between $f k s 1$ and $c p s 1$ mutants, the roles of $c p s 1^{+}$ may differ in some aspects from those of FKS1. Unlike $F K S 1$, cps $1^{+}$does not contain any apparent MCB cis-element in its promoter region, which also plays a role in $S$. pombe gene expression in the late $\mathrm{G}_{1} / \mathrm{S}$ phases (Tanaka et al., 1992). Moreover, $c p s 1^{+}$appears to be more related to cytokinesis and cell polarity than those of FKS genes, since the mutant cells display multiseptated and branched morphology when cultured in the presence of an osmotic stabilizer at the restrictive temperature (in the absence of 1.2 M sorbitol, cps1-12 cells are swollen and eventually lysed at $37^{\circ} \mathrm{C}$ ). This point will be discussed again in the last section.

S. pombe thermosensitive mutants were isolated, which required the presence of osmotic stabilizer to survive and grow at a nonpermissive temperature. (Ribas et al., 1991a). Under restrictive conditions, the mutant bearing $c w g 2-1$ shows both a reduced amount of cell wall $\beta$-glucan and lower levels of in vitro 1,3- $\beta$-glucan synthase activity than the wild type. Cloning and molecular characterization have demonstrated that $c w g 2^{+}$is a structural and functional homolog of S. cerevisiae CDC43/CAL1, coding a $\beta$ subunit 
Table 1. Genes involved in cell wall integrity

\begin{tabular}{|c|c|c|c|}
\hline Gene $^{a}$ & Gene product ${ }^{b}$ & Mutant phenotype $^{\mathrm{b}}$ & References \\
\hline $\operatorname{cwg} 1^{+}$ & unknown & $\begin{array}{l}\text { osmotic fragile, reduced amount of } \\
\beta \text {-glucan, lower level of in vitro } \beta \text {-glucan } \\
\text { synthase activity }\end{array}$ & Ribas et al., 1991a \\
\hline $\operatorname{cwg} 2^{+}$ & GGT-I $\beta$ subunit & the same as cwg 1 & $\begin{array}{l}\text { Ribas et al., 1991a } \\
\text { Diaz et al., } 1993\end{array}$ \\
\hline$c p s 1^{+}$ & $\begin{array}{l}1,3 \text { - } \beta \text {-glucan synthase } \\
\text { catalitic subunit }(F K S \\
\text { gene homolog) }\end{array}$ & $\begin{array}{l}\text { CIPC, CsA, PaB hypersensitive, } \\
\text { swollen and eventually lyse at } 37^{\circ} \mathrm{C}\end{array}$ & Ishiguro et al., 1997 \\
\hline rho1 $^{+}$ & $\begin{array}{l}\text { small GTP-binding } \\
\text { protein }\end{array}$ & $\begin{array}{l}\text { OP- } r h o 1^{+} \text {: complementing } c w g 2 \text { phenotype, } \\
\text { thickened cell wall, round and branched cell } \\
\text { shap }\end{array}$ & $\begin{array}{l}\text { Nakano and Mabuchi, } 1995 \\
\text { Arellano et al., } 1996 \\
\text { Nakano et al., } 1997\end{array}$ \\
\hline$r h o 2^{+}$ & $\begin{array}{l}\text { small GTP-binding } \\
\text { protein }\end{array}$ & $\begin{array}{l}\text { OP- } r h o 2^{+} \text {: thickened cell wall, } \\
\text { round cell shape }\end{array}$ & Hirata et al., 1998 \\
\hline $\operatorname{kin} 1^{+}$ & protein kinase & $\begin{array}{l}\Delta k i n 1 \text { : round cell shape, } \\
\text { sensitive to } \beta \text {-glucanase }\end{array}$ & Levin and Bishop, 1990 \\
\hline pck $2^{+}$ & PKC homolog & $\begin{array}{l}\Delta p c k 2: \text { irregular cell shape, OP-pck } 2^{+}: \text {lethal, } \\
\text { multiseptated and branched cell shape }\end{array}$ & $\begin{array}{l}\text { Toda et al., } 1993 \\
\text { Kobori et al., } 1994\end{array}$ \\
\hline $\begin{array}{l}p m k 1^{+} / \\
\operatorname{spm} 1^{+}\end{array}$ & MAPK homolog & $\begin{array}{l}\Delta p m k 1 \text { :sensitive to } \beta \text {-glucanase, } \\
\text { aberrant cell shape, cytokenesis } \\
\text { defect }\end{array}$ & $\begin{array}{l}\text { Toda et al., } 1996 \\
\text { Zaitsevskaya-Carter and Cooper, } 1997\end{array}$ \\
\hline$m k h 1^{+}$ & MEKK homolog & $\begin{array}{l}\Delta m k h 1 \text { : round cell shape, } \\
\text { sensitive to } \beta \text {-glucanase and } \\
\text { high } \mathrm{KCl} \text { or } \mathrm{NaCl} \text { concentrations, } \\
\text { cytokinesis defect }\end{array}$ & Sengar et al., 1997 \\
\hline$p a b 1^{+}$ & $\begin{array}{l}\text { PP2A regulatory } \\
\text { subunit PR55 }\end{array}$ & $\begin{array}{l}\triangle p a b 1 \text { : round cell shape, } \\
\text { sensitive to } \beta \text {-glucanase, } \\
\text { aberrant distributions of actin and } \\
\text { microtubules, cytokinesis delay }\end{array}$ & Kinoshita et al., 1996 \\
\hline$c w l 1^{+}$ & $27 \mathrm{kDa}$ protein & OP-cwl1 $1^{+}$: cell lysis, cytokinesis defect & Godoy et al., 1996 \\
\hline $\begin{array}{l}\operatorname{pap} 1^{+} / \\
\operatorname{sph} 1^{+}\end{array}$ & unknown & $\begin{array}{l}\text { PaB resistant, round cell shape, } \\
\text { sensitive to } \alpha \text {-glucanase, } \\
\text { reduced amoun of galactomannan }\end{array}$ & Ribas et al., 1991b \\
\hline $\operatorname{srb} 1^{+}$ & unknown & $\begin{array}{l}\text { hypotonic fragile, swollen cell shape, } \\
\text { reduced amoun of galactomannan }\end{array}$ & Belda and Zarate, 1996 \\
\hline swo $1^{+}$ & hsp90 homolog & swollen and lyse at high temperature & Aligue et al., unpublished ${ }^{c}$ \\
\hline $\begin{array}{l}\operatorname{cps} 8^{+} / \\
\operatorname{act} 1^{+}\end{array}$ & actin & $\begin{array}{l}\text { enlarged and branched cell shape, } \\
\text { cytokinesis defect, lethal at } 37^{\circ} \mathrm{C} \text {, }\end{array}$ & Ishiguro and Kobayashi, 1996 \\
\hline
\end{tabular}

${ }^{a}$ Genes are listed in the order in which they are described in the text.

b Abbreviations used are GGT-I, geranylgeranyltransferase type I; PKC, protein kinase C; MAPK, MAP (mitogen-activated protein) kinase; MEKK, MAP kinase kinase kinase; PP2A, protein phosphatase 2A; hsp, heat shock protein; CsA, cyclosporin A; CIPC, isopropyl N-3-chlorophenyl carbamate; $\mathrm{PaB}$, papulacandin B; OP, overexpression; $\Delta$, disruption.

${ }^{c}$ see referece of Shiozaki et al. (1994).

of a geranylgeranyltransferase type I (Diaz et al., 1993). Since the reduction of in vitro glucan synthase activity in the mutant cells is caused by a detergent-soluble fraction, Cwg2 would be responsible for the geranylgeranylation of the GTP-binding component of glucan synthase. The isolation of S. pombe cdc42 ${ }^{+}$(Fawell et al., 1992; Miller and Johnson, 1994) and rho1 (Nakano and Mabuchi, 1995) permitted to test for their ability to complement cwg2-1 mutant phenotypes (Arellano et al., 1996). Only Rho1 but not Cdc42 is able to partially complement a defect in glucan synthase activity under restrictive conditions, and $r h o 1^{+}$ overexpressed cells display aberrant cell morphology with thickened walls and become more sensitive to papulacandin $\mathrm{B}$ or cell wall degrading enzymes. Considering these collective results and the findings that Rho1 is a regulatory subunit of $S$. cerevisiae 1,3- $\beta$-glucan synthase (Drgonova et al., 1996; Mazur and Baginsky, 1996; Qadota et al., 1996), it could be concluded that, in $S$. pombe, Rho1 also serves as a regulatory subunit of 1,3- $\beta$-glucan synthase, and Cwg2 (GGT-I $\beta$ subunit) is essential for targeting the Rho1 
GTPase to the plasma membrane in order to activate the catalytic subunit of 1,3- $\beta$-glucan synthase (Diaz et al., 1993; Arellano et al., 1996; Nakano et al., 1997). Very recently, it has also been shown that $S$. pombe $r h o 2^{+}$is involved in cell wall integrity. The overexpression of the $r h o 2^{+}$thickens cell wall, and the gene disruption ( $\Delta r h o 2)$ enhances sensitivity to aculeacin A (an inhibitor of $\beta$-glucan synthase) and $\beta$-glucanase treatment (Hirata et al., 1998). Although $r h o 2^{+}$is involved in cell wall integrity and growth polarity, how this gene interacts with 1,3 - $\beta$-glucan synthesis remains to be clarified.

Genes in signaling pathways involved in cell wall integrity. Several components of signal transduction pathways other than the small GTP-binding proteins have also been shown to be responsible for cell wall integrity. A kin $1^{+}$which encodes a putative protein kinase was isolated in $S$. pombe and found to be related to cell morphogenesis and wall integrity (Levin and Bishop, 1990). $\Delta$ kin 1 cells show spherical rather than cylindrical growth, as well as different sensitivities to lysis by treatment with $\alpha$ - and $\beta$-glucanases (Novozym 234 and Zymolyase-20T, respectively), suggesting an alteration in their wall composition or organization.

$S$. pombe has two novel protein kinase C-like genes, $p c k 1^{+}$ and $p c k 2^{+}$, which share an overlapping essential function for cell viability (Toda et al., 1993). $\Delta p c k 2$ cells display bending or pear-like morphology, and overexpression of the gene confers cell lethality with multiseptated and branched cell shape (Toda et al., 1993). Using a protoplast-regenerating system, it was found that any new cell wall materials and normal actin distribution cannot be generated in the $\Delta p c k 2$ protoplast, demonstrating the crucial roles of $p c k 2^{+}$in cell wall synthesis and actin organization (Kobori et al., 1994). It should be noted however that although $p c k 1^{+}$is not essential for protoplast regeneration, it could have a minor role because the regeneration frequency in $\Delta p c k 1$ is half that of the wild-type (Kobori et al., 1994).

A gene of the MAP Kinase pathway showing about $65 \%$ predicted amino acid sequence identity with $S$. cerevisiae Mpk1p was isolated independently, and named $p m k 1^{+}$ (Toda et al., 1996a) and spm $1^{+}$(Zaitsevskaya-Carter and Cooper, 1997). $\Delta p m k 1$ cells are viable but exhibit pleiotropic phenotypes which display cell wall weakness, abnormal cell shape, cytokinesis defects, and an altered sensitivity to cations. These defective phenotypes can be partially rescued by the multicopy expression of $S$. cerevisiae $M P K 1$ and frog X-MAPK. $\Delta p m k 1$ cells become more sensitive to $\beta$-glucanase treatment than $\Delta p c k 2$ cells, and a synergistic effect in this sensitivity is observed in the double disruptant cells. $\beta$-glucanase sensitivity in $\Delta p m k 1$ cells is partially suppressed by $p c k 1^{+}$-bearing multicopy plasmids. In contrast, $p m k 1^{+}$has only a small effect in $\Delta p c k 2$ cells. Thus, these two pathways, Pck1Pck2 and Pmk1, are not functioning in a linear manner, but somehow regulate cell integrity in a coordinated manner (Toda et al., 1996a). It was also shown that Spm1 is activated in response to osmotic and heat stresses, and under such conditions $\Delta s p m 1$ cells grow as short branched filaments with thickened cell walls and septa (ZaitsevskayaCarter and Cooper, 1997). The findings that the $\Delta$ wis1 $\Delta$ spm1 double mutant shows a synergistic phenotype of each disruptant, and Spm1 is tyrosine phosphorylated normally in $\Delta$ wis 1 cells suggest that $\mathrm{Spm} 1$ is a second type of MAP kinase involved in osmoregulation.

More recently, $m k h 1^{+}$has been isolated as a MEK kinase, the amino acid sequence of its putative catalytic domain is $54 \%$ identical to that of $S$. cerevisiae Bck1p (Sengar et al., 1997). The $\Delta m k h 1$ phenotypes are essentially identical to those observed in the cells lacking $\mathrm{pmk1}^{+} /$ spm $1^{+}$. In addition, $\Delta m k h 1$ cells exhibit filamentous multiseptate morphology when grown on a hyperosomotic medium containing $1.0 \mathrm{M}$ sorbitol or $0.6 \mathrm{M} \mathrm{KCl}$. Mkh1 is thus required for the completion of cytokinesis under elevated temperatures or hyperosmotic conditions. Double mutants and gene complementation experiments suggest that Pck1, Pck2, and Mkh1 act independently to maintain cell wall integrity and that Pmk1/Spm1 acts downstream from Mkh1 (Sengar et al., 1997). Interestingly, defect phenotypes with respect to polarized cell growth and cell wall integrity were found in cells which lack a regulatory subunit of protein phosphatase 2A (PP2A), pab1 $1^{+}$ (Kinoshita et al., 1996). $\quad \Delta p a b 1$ cells show defects in actin distribution and microtubules organization as well.

Other genes involved in cell wall integrity. $c w l 1^{+}$ was isolated as a gene that causes cell lysis when it is overexpressed in the absence of an osmotic stabilizer (Godoy et al., 1996). This gene codes for a polypeptide which contains 308 amino acids, and shows no significant homology with any known protein in the current databases. Cells which overexpress the gene also display a cytokinesis defect, and the gene disruption causes no obvious phenotype. pap1/sph1 was identified as a mutation which confers PaB resistance and a round cell shape (Ribas et al., 1991b). The mutant shows more sensitivity to $\alpha$-glucanase treatment and a reduced amount of galactomannan fraction in the wall. A hypotonic fragile mutant, $s r b 1^{+}$, was also shown to contain a significantly decreased amount of galactomannan and a simultaneously increased amount of $\alpha$ - and $\beta$-glucan in the cell wall (Belda and Zarate, 1996). The products of $p a p 1^{+} / \operatorname{sph} 1^{+}$and $s r b 1^{+}$are thus critical for the maintenance of wall compositions and integrity, but the gene products have not yet been identified. swo $1^{+}$ codes for a homolog of heat shock-protein hsp90, and the disruption causes cell lysis at high temperatures (Aligue et al., unpublished data).

The actin cytoskeleton is essential for cell wall deposition at the growing region of the cell surface. The $S$. pombe actin mutation, cps 8 , causes defects in polarized cell 
growth and cytokinesis, resulting in the formation of abnormally enlarged and branched cells containing several nuclei and aberrant septa (Ishiguro and Kobayashi, 1996). A recent electron microscopic study has demonstrated that the structure of cps 8 cell wall is very disorganized, showing irregularly thickened and partially stratified structures (Ishijima et al., and Konomi et al., 14th International Congress on Electron Microscopy, Mexico, 1998). The double mutant cells of cps 1 and cps 8 display a swollen morphology particularly in a rich culture medium at stationary phase (Ishiguro, unpublished data). These phenotypes are suppressed to a significant extent in the presence of an osmotic stabilizer.

\section{GENETIC INTERACTIONS AMONG GENES INVOLVED IN CELL WALL INTEGRITY AND CELL MORPHOGENESIS}

Actin cytoskeleton and cell wall synthesis. Fission yeast cells grow by apical extension until mitosis begins. Following cytokinesis, cell growth takes place at one end (the old end) in newly divided cells and extension of both ends begins at a point one-third into the cell cycle, the event termed "new end take off" (NETO) (Mitchison and Nurse, 1985). This is easily recognizable by staining the cells with calcofluor which has a strong chemical affinity to cell wall materials (Robinow and Hyams, 1989). The coincidence of a distribution of cortical actin patches with calcofluor staining in the growing ends or medial region of cells is always observed, suggesting a tight linkage between actin distribution and cell wall deposition (Marks and Hyams, 1985; Marks et al., 1986). Ultrastructure analysis by electron microscopy using freeze-substituted cells also showed that a distribution of cytoplasmic vesicles and filasomes, microfilament-associated structures, was coincident with the region of cell wall synthesis (Kanbe et al., 1989). In regenerating protoplasts, a high dose of cytochalasin $\mathrm{D}$, a potent inhibitor of actin organization, completely inhibits the formation of the fibrillar net structure (Kobori et al., 1989), which is composed largely of 1,3- $\beta$-glucan (Osumi et al., 1989). Thus, it is undisputed that the actin cytoskeleton plays a crucial role in cell wall synthesis, either directly or indirectly.

In $S$. cerevisiae, certain temperature-sensitive act 1 mutants have been shown to become enlarged and rounded at the restrictive temperature, in which actin is abnormally distributed and secretory vesicles accumulate (Novick and Botstein, 1985). In such cells, the wall structure was also aberrant; the fibrillar network is loose and the amorphous component is deficient, suggestive of a defect in exocytosis of the wall materials. The mutant cell wall varies in thickness in different areas of its surface under such conditions (Gabriel and Kopecka, 1995). As mentioned in the preceding section, the $S$. pombe actin mutant (cps8) also displays an aberrant cell wall structure. Interestingly, the expression of constitutively active Rho1 in S. pombe cells induces a similar stratified aberrant wall structure as well as delocalization of actin patches (Nakano et al., 1997). The actin cytoskeleton must be required for transporting wall materials and even $\beta$-glucan synthase itself to the plasma membrane, unless the cell is incapable of establishing and sustaining cell polarity during the cell cycle. Thus, Rho1 GTPase functions both in the 1,3- $\beta$ glucan synthesis and the actin organization to establish polarized cell growth (Arellano et al., 1997).

Cell morphogenesis and cell wall synthesis. Figure 1 shows a schematic diagram of the genes and events involved in wall synthesis and cell morphology. Under conditions that induce aberrant cell wall synthesis, the cells always show a simultaneous loss of polarity and defects in cell separation (see Table 1), indicating that normal cell wall synthesis is essential for both polarized cell growth and the cell division process. Cell wall synthesis is thus one of the crucial prerequisites for development and maintenance of cell morphology during the cell cycle. Another prerequisite might be an actin organization, which is required for the establishment of cell polarity. A considerable number of genes that are involved in polarized growth have been identified thus far, ras1 null mutant cells were first found to become round (Fukui et al., 1986), and mutants showing phenotypes similar to ras1 null were isolated and named ral1 through ral4 (Fukui and Yamamoto, 1988). These and other genes (see Fig. 1) are engaged in a Ras1-Ral1-Cdc42 small GTP-binding protein pathway and its effector, Pak1/Shk1, which are responsible for the maintenance of cell polarity as well as mating response (Fukui et al., 1989; Hughes et al., 1990; Imai et al., 1991; Miller and Johnson, 1994; Chang et al., 1994; Ottilie at al., 1995; Marcus et al., 1995; Gilbreth et al.,1996; Song et al., 1996). In S. cerevisiae, Rsr1/Bud1-Cdc24Cdc42 pathway has been shown to be essential for bud site selection, bud emergence and shmoo projection for mating, and thus involved in the establishment and maintenance of cell polarity (see Chant, 1994; Cid et al., 1995; Drubin and Nelson, 1996, for reviews). The Cdc42 GTPases appear to activate protein kinase, Pak1/Shk1 (S. pombe) and Ste20p (S. cerevisiae), respectively. These protein kinases function to transmit mating signals to downstream MAP kinase cascade, Byr2-Byr1-Spk1 in S. pombe and Ste11-Ste7-Fus3 and Kss1 in S. cerevisiae, respectively (see Herskowitz, 1995, for review; Tu et al., 1997). Fission yeast Ral3/Scd2, which contains two SH3 domains in the $\mathrm{N}$-terminus and forms protein complex with Ras1-GTP, Ral1 and Cdc42, was shown to be homologous to budding yeast Bem1p. These factors are also required for normal cell morphology and mating. Thus, there seems to be a structural and functional similarity between the two yeast small GTP-binding protein pathways and their effectors, Pak1/Shk1 or Ste20, in terms of polarized cell growth and 


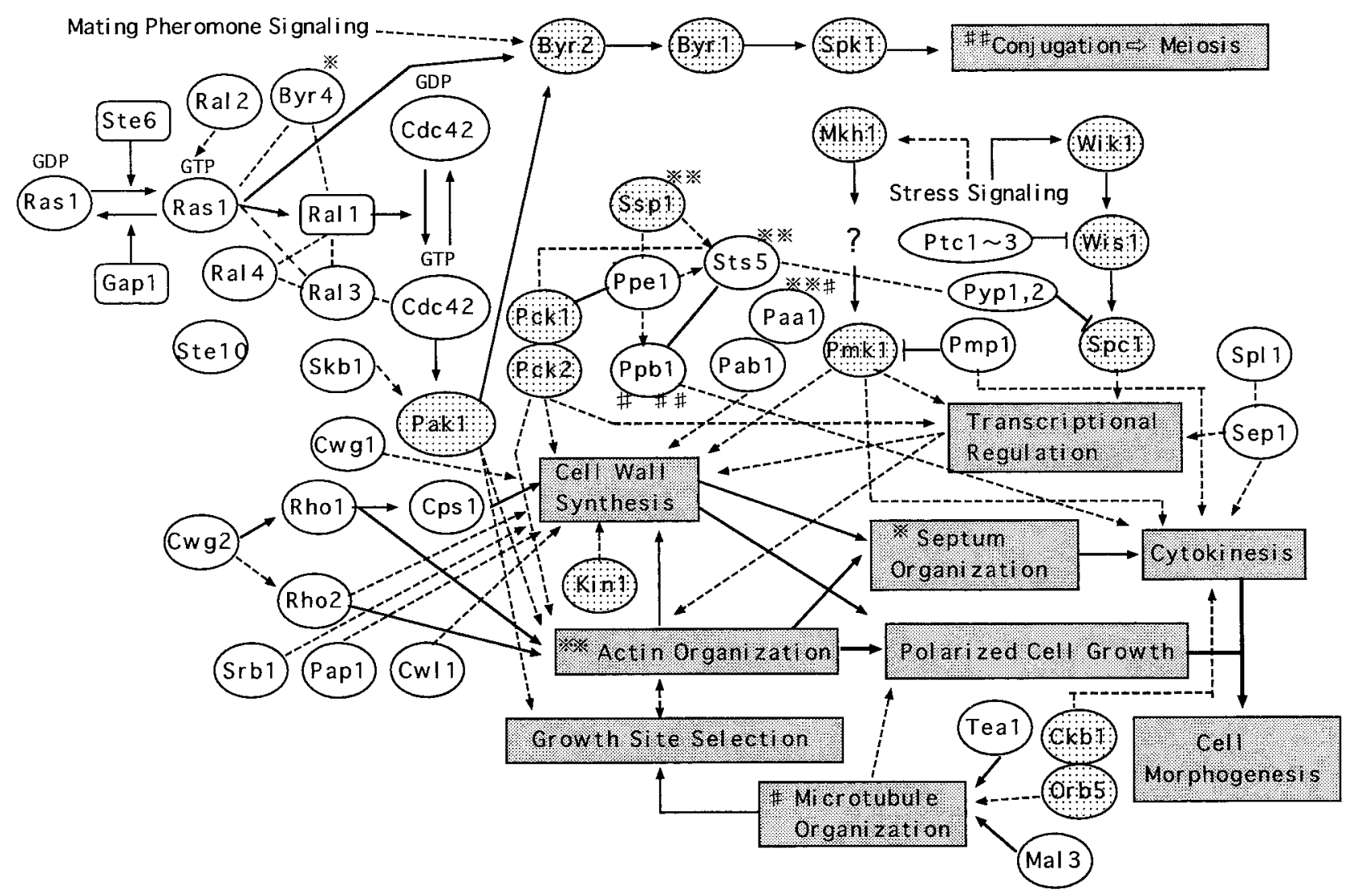

Fig. 1. A schematic diagram of the genes and events involved in wall synthesis and cell morphology. All genes thus far reported are not necessarily shown. The genes encompassed with dotted circles code for protein kinases. Genetic and functional relationships are indicated by dotted and solid lines; dotted line indicates a potential or indirect interaction and a solid line a more evident or direct interaction. Relationship between gene and cellular event is also indicated by using characters, ※ (septum organization), ※※ (actin organization), \# (microtubule organization), and \#\# (conjugation). Arrows indicate epistatic or promotive actions and a $\mathrm{T}$ shape symbol a suppressive one. For details see text.

mating signal transduction. Such two events may be linked each other in part, possibly via common factors that may regulate actin organization. However, it should be noted that morphological phenotypes of $c d c 42$ mutants are different between the two yeasts. S. cerevisiae $c d c 42-1^{\text {ts }}$ mutants display a large, round and multinucleate cell morphology at the restrictive temperature (Adams et al., 1990), while $S$. pombe null phenotype of the counterpart is an arrest as small, round, dense cells (Miller and Johnson, 1994). A constitutively active Cdc42p confers dominantlethal phenotype in the budding yeast (Ziman et al., 1991), but does not in S. pombe (Miller and Johnson, 1994). The ste10 gene was also found to confer rounded cell shape but the product of this gene has not yet been identified (Leupold, 1991).

Another group of genes whose disruption causes defects in cell morphology and often cytokinesis has been identified, which falls into the class of protein phosphatases. Null alleles of ppe1/esp1, a type 2A-like protein phosphatase (PP2A), and ppb1, a type 2B protein phosphatase (PP2B, calcineurin), cause short, pear-shaped or multiseptate, branched cells, respectively (Shimanuki et al., 1993; Matsumoto and Beach, 1993; Yoshida et al., 1994). Phenotypes of $\Delta p p e 1$ are suppressed by $p c k 1^{+}$and double disruptant becomes lethal, suggesting that this phosphatase interacts with Pck1 that plays a minor role in regenerating protoplasts (Kobori et al., 1994). A sppe1 $\Delta p p b 1$ double mutant displays a pear-shaped cell, indicating that $p p e 1^{+}$acts epistatically over $p p b 1^{+}$(Yoshida et al., 1994). A novel MAP kinase phosphatase gene, $p m p 1^{+}$, was recently isolated, which shares an essential function with $p p b 1^{+}$in cytokinesis and other cell responses (Sugiura et al., 1998). Pmp1 acts as a negative regulator of MAP kinase Pmk1, which is essential for cell wall synthesis (see preceding section). The regulatory subunits of PP2A, Paa1(PR65), and Pab1 (PR55), are also essential for cell morphogenesis via regulating actin or the microtubule cytoskeleton; the null allele of the latter gene also causes a defect in cell wall synthesis (Kinoshita et al., 1996). A double disruptant of the type $2 \mathrm{C}$ like-protein phosphatases (PP2C), ptc1 and ptc3, displays a swollen, pear-like cell shape and temperature-sensitive cell lysis which can be 
suppressed by an osmotic stabilizer (Shiozaki and Russell, 1995). The double mutant, however, shows the same sensitivity to $\beta$-glucanase treatment as that in wild-type, suggesting that the mutant cells have a normal cell wall structure (Shiozaki and Russell, 1995).

Two genes which interact with some of these protein phosphatases have also been identified. One is a sts $5^{+}$ (staurosporine-supersensitive), whose mutation causes defects in cell morphology and cortical actin distribution (Toda et al., 1991). The mutation is synthetically lethal with $\Delta p p e 1$ and is suppressed by multicopy-plasmids bearing $p c k 1^{+}$or $p y p 1^{+}$(Toda et al., 1996b). sts $5^{+}$which encodes a $130 \mathrm{kDa}$ protein with sequence similarity to Dis3 is essential for polarized growth. However, the sts 5 mutant shows no defect in cell wall integrity. Spontaneous revertants were isolated from either $\Delta p p e 1$ or sts5-7 mutants, and a gene complementing the temperature-sensitive phenotype of the revertant was isolated (Matsusaka et al., 1995). The gene, named $\operatorname{ssp} 1^{+}$, was found to code for a novel protein kinase. The ssp1 mutant cells grow only in a monopolar manner, in which cortical actin is localized only at the growing end, suggesting that Ssp1 protein kinase plays a role in cortical actin reorganization, which is required for NETO during the cell cycle. Sts5 is thought to be a possible substrate for Ssp1 kinase and Ppe1 phosphatase in an antagonistic manner (Matsusaka et al., 1995).

As previously described, the double disruptant of wis 1 and spm 1 shows a synergistic phenotype of each disruptant and the PP2C double disruptant ( $p t c 1$ and $p t c 3$ ) is defective in polarized growth. Since the PP2C and the Pyp tyrosine phosphatases are acting as a negative regulator in Wis1 and Spc1, respectively (Shiozaki et al., 1994; Millar et al., 1995; Shiozaki and Russell, 1995; Degols et al., 1996; Samejima et al., 1997; Shiozaki et al., 1997), the Wis1-Spc1 stress-responsive MAP kinase pathway may also play some roles in cell morphogenesis via the control of actin organization under hyperosmotic or thermal stress conditions. Other genes, such as the $\operatorname{sep} 1^{+}$(a homolog of the HNF-3/ forkhead family of transcription factors) and its functionally related gene, $s p l 1^{+}$(unknown) have been identified as being responsible for cell morphogenesis, whose mutations confer branching mycelial or bent cell shape with cytokinesis defects (Sipiczki et al., 1993; Ribar et al., 1997). However, the involvement of these factors in wall biogenesis is unclear.

Recently, systematic research has been carried out in order to identify genes which regulate cell morphogenesis. The mutant or related alleles can be grouped into several classes, according to their morphological characteristics: 12 orb genes (spherical), two tea genes (branched), and five ban genes (curved) (Nurse, 1994; Snell and Nurse, 1994; Verde et al., 1995), and the total 43 gam genes (Hirata et al., 1998) have been identified. One of these, orb5 ${ }^{+}$, was found to code for a homolog of casein kinase II $\alpha$ whose mutation gives rise to a spherical cell shape (Snell and Nurse, 1994). A positive regulator of the casein kinase II $\beta$ subunit, Ckb1, was also shown to be responsible for cell morphology and cytokinesis (Roussou and Draetta, 1994). Studies of double mutant phenotypes between orb5-19 and various cdc mutants suggest that this protein kinase plays a role in the translation of cell polarity into polarized growth, possibly interacting with microtubular function. In the mutant cells, cell wall synthesis is thought not to be disturbed (Snell and Nurse, 1994). The tea1 mutant mislocalizes the site of growth, resulting in branched and curved cells. Cloning of the gene allowed Tea1 localization to be determined, showing that the protein is tightly located at the cell poles, where the ends of microtubules are present (Mata and Nurse, 1997). It has been suggested that Tea1 acts as a positional maker that directs the growth machinery to the cell poles. Interestingly, a mutant showing phenotypes very similar to those of the tea mutants was isolated from a screening of higher frequency minichromosome loss and which showed sensitivity to the microtubule-destabilizing drug thiabendazole (Beinhauer et al., 1997). The mal3 $^{+}$gene responsible for the phenotypes was cloned and found to be a functional homolog of human EB-1 (Beinhauer et al., 1997), which has been identified as interacting with the tumour-suppressor protein APC (Su et al., 1995). Mal3 is a microtubule-associated protein and its disruption causes altered interphase microtubule arrays, suggesting that this protein also plays a role in determining the direction of cell poles via microtubule organization.

\section{PROSPECTS AND PROBLEMS}

The fungal cell wall is composed of numerous components which are interwoven with one another to a considerable extent. Wall polymers such as 1,6- $\beta$-glucan and glycoproteins are likely to be synthesized and processed along the secretory pathway and transported to the outer side of plasma membrane. In S. cerevisiae, mutations of GPI anchoring (gpi1 and gpi2) and the GPI-anchored protein (gas1/ggp1) itself confer morphological abnormalities, and the latter mutant also shows a severe defect in in vivo 1,3and 1,6- $\beta$-glucan synthesis (see Klis, 1994; Orlean, 1997 for reviews). A number of genes which are involved in 1,6$\beta$-glucan synthesis and other factors responsible for normal cell wall assembly have been identified in the budding yeast. However, in $S$. pombe, little is known about such wall and secretory pathway genes, and even genetic and biochemical studies of 1,3- $\beta$-glucan synthesis have just begun. In $S$. cerevisiae, at least two alternative subunits, Fks1p and Fks2p are sufficient for total 1,3- $\beta$-glucan synthase activity. In $S$. pombe, the issue of how many functional genes for the1,3- $\beta$-glucan synthase catalytic subunit exist and how they are coordinately controlled in the cell cycle and in response to external stimuli is still 
unclear. The budding yeast FKS1 is regulated at the transcriptional level through MCB and SCB cis-elements in a cell cycle dependent manner under the vegetative growth conditions and the alternative FKS2 through discrete two promoter elements by calcineurin and the cell integrity pathway component in parallel under thermal stress conditions (Mazur et al., 1995; Zhao et al., 1998). Is Cps1 a major $\beta$-glucan synthase for optimal growth conditions as Fks1p or does it have another specific role, such as that of an Fks2p? It is also unclear whether Pck1 and Pck2 (PKC) act downstream from Rho1, and in turn whether the PKC acts as an upstream regulator of Pmk1, like the budding yeast cell integrity pathway (Rho1p $\rightarrow$ Pkc1p $\rightarrow$ Mpk1p). Interestingly, $\triangle P K C 1$ cells show more severe lytic phenotypes than cells lacking the following MAP kinase components, while $\Delta p c k 2$ cells are less sensitive to $\beta$-glucanase than $\triangle p m k 1$ cells (Toda et al., 1996).

Fission yeast cell wall mutants show simultaneous defects in cell shape and cytokinesis (see Table 1). This implies that a complete cell wall structure is either required for the normal execution of cytokinesis or that functional interactions between wall synthesis and the cell division process exist via common signals, or both. In fact, we have noted that double mutants of $c p s 1$ with certain septation mutations generate a more weakened cell wall (higher sensitivity to wall degradation enzyme) than in each parental mutant strain and that completely deformed cells with aberrant actin distribution are observed even at the permissive temperature in certain double mutants (Ishiguro and Saitou, UK-Japan Cell Cycle Workshop, Kyoto, 1997). For example, double mutations of cps1 with $c d c 3$, $c d c 15$ or $c d c 16$ (Nurse et al., 1976; Minet et al., 1979) cause defects in polarized cell growth and cell wall integrity even at the permissive temperature. These results imply that a profilin homolog $\mathrm{Cdc} 3$ (Balasubramanian et al., 1994), an SH-domain-containing protein, Cdc15 (Fankhauser et al., 1995), and a mitotic-checkpoint protein, Cdc16 (Fankhauser et al., 1993) may have some interactions with $\beta$-glucan synthesis, possibly via actin organization. To clarify the molecular mechanisms of such interactions between the actin cytoskeleton and $\beta$-glucan synthesis would expand our understanding of not only fungal cell wall synthesis but also of eukaryotic cell morphogenesis in general.

\section{REFERENCES}

Adams, A. E. M., Johnson, D. I., Longnecker, R. M., Sloat, B. F., and Pringle, J. R. (1990) CDC42 and CDC43, two additional genes involved in budding and the establishment of cell polarity in the yeast Saccharomyces cerevisiae. J. Cell Biol. 111, 131-142.

Arellano, M., Durán, A., and Pérez, P. (1996) Rho1 GTPase activates the (1-3)- $\beta$-D-glucan synthase and is involved in Schizosaccharomyces pombe morphogenesis. EMBO J. 15, 4584-4591.

Arellano, M., Duran, A., and Perez, P. (1997) Localisation of the
Schizosaccharomyces pombe rho1p GTPase and its involvement in the organisation of the actin cytoskeleton. J. Cell Sci. 110, 2547-2555.

Bacon, J. S. D., Jones, D., Farmer, V. C., and Webley, D. M. (1968) The occurrence of $\alpha$ (1-3) glucan in Cryptococcus, Schizosaccharomyces and Polyporus species, and its hydrolysis by a Streptomyces culture filtrate lysing cell walls of Cryptococcus. Biochim. Biophys. Acta 158, 313-315.

Balasubramanian M. K., Hirani, B. R., Burke, J. D., and Gould, K. L. (1994) The Schizosaccharomyces pombe $c d c 3^{+}$gene encodes a profilin essential for cytokinesis. J. Cell Biol. 125, 12891301.

Beinhauer, J. D., Hagan, I. M., Hegemann, J. H., and Fleig, U. (1997) Mal3, the fission yeast homologue of the human APCinteracting protein EB-1 is required for microtubule integrity and the maintenance of cell form. J. Cell Biol. 139, 717-728.

Belda, F., and Zárate, V. (1996) Isolation and characterization of Schizosaccharomyces pombe fragile mutants. Yeast 12, 555564.

Bowen, A. R., Chen-Wu, J. L., Momany, M., Young, R., Szaniszlo, P. J., and Robbins, P. W. (1992) Classification of fungal chitin synthases. Proc. Natl. Acad. Sci. USA 89, 519-523.

Bush, D. A., Horisberger, M., Horman, I., and Wursch, P. (1974) The wall structure of Schizosaccharomyces pombe. J. Gen. Microbiol. 81, 199-206.

Castro, C., Ribas, J. C., Valdivieso, M. H., Varona, R., del Rey, F., and Duran, A. (1995) Papulacandin B resistance in budding and fission yeasts: Isolation and characterization of a gene involved in $(1,3) \beta$-D-glucan synthesis in Saccharomyces cerevisiae. J. Bacteriol. 177, 5732-5739.

Chang, E. C., Barr, M., Wang Y., Jung, V., Xu, HP., and Wigler, M. H. (1994) Cooperative interaction of S. pombe proteins required for mating and morphogenesis. Cell 79, 131-141.

Chant, J. (1994) Cell polarity in yeast. Trends Genet. 10, 328333.

Cid, V. J., Durán, A., del Rey, F., Snyder, M. P., Nombela, C., and Sánchez, M. (1995) Molecular basis of cell integrity and morphogenesis in Saccharomyces cerevisiae. Microbiol. Rev. 59, 345-386.

Degols, G., Shiozaki, K., and Russell, P. (1996) Activation and regulation of the $\mathrm{Spc} 1$ stress-activated protein kinase in Schizosaccharomyces pombe. Mol. Cell. Biol. 16, 2870-2877.

Diaz, M., Sanchez, Y., Bennett, T., Sun, C. R., Godoy, C., Tamanoi, F., Duran, A., and Perez, P. (1993) The Schizosaccharomyces pombe cwg $2^{+}$gene codes for the $\beta$ subunit of a geranylgeranyltransferase type I required for $\beta$-glucan synthesis. EMBO J. 12, 5245-5254.

Douglas, C. M., Foor, F., Marrinan, J. A., Morin, N., Nielsen, J. B., Dahl, A. M., Mazur, P., Baginsky, W., Li, W., El-Sherbeini, M., Clemas, J. A., Mandala, S. M., Frommer, B. R., and Kurtz, M. B. (1994) The Saccharomyces cerevisiae FKS1 (ETG1) gene encodes an integral membrane protein which is a subunit of 1,3- $\beta$-D-glucan synthase. Proc. Natl. Acad. Sci. USA 91, 12907-12911.

Drgonová, J., Drgon, T., Tanaka, K., Kollár, R., Chen, G-C., Ford, R. A., Chan, C. S. M., Takai, Y., and Cabib, E. (1996) Rho1p, a yeast protein at the interface between cell polarization and morphogenesis. Science 272, 277-279.

Drubin, D. G., and Nelson, W. J. (1996) Origins of cell polarity. Cell 84, 335-344.

Eng, W-K., Faucette, L., McLaughlin, M. M., Cafferkey, R., Koltin, Y., Morris, R. A., Young, P. R., Johnson, R. K., and Livi, G. P. (1994) The yeast FKS1 gene encodes a novel membrane protein, mutations in which confer FK506 and cyclosporin A hypersensitivity and calcineurin-dependent growth. Gene 151, 61-71. 
Fawell, E., Bowden, S., and Armstrong, J. (1992) A homologue of the ras-related $C D C 42$ gene from Schizosaccharomyces pombe. Gene 114, 153-154.

Fankhauser, C., Reymond, A., Cerutti, L., Utzig, S., Hofmann, K., and Simanis, V. (1995) The S. pombe $c d c 15$ gene is a key element in the reorganization of $\mathrm{F}$-actin at mitosis. Cell $\mathbf{8 2}$, $435-444$.

Fankhauser, C., Marks, J., Reymond, A., and Simanis, V. (1993) The $S$. pombe $c d c 16$ gene is required both for maintenance of p34 ${ }^{\text {cdc2 }}$ kinase activity and regulation of septum formation: a link between mitosis and cytokinesis? EMBO J. 12, 26972704.

Fleet, G. H. (1991) Cell walls. In: The Yeasts (eds.: A. H. Rose, and J. S. Harrison), pp. 199-277. Academic Press, San Diego.

Fukui, Y., Kozasa, T., Kaziro, Y., Takeda, T., and Yamamoto, M. (1986) Role of a ras homolog in the life cycle of Schizosaccharomyces pombe. Cell 44, 429-336.

Fukui, Y., Miyake, S., Satoh, M., and Yamamoto, M. (1989) Characterization of the Schizosaccharomyces pombe ral2 gene implicated in activation of the ras 1 gene product. Mol. Cell. Biol. 9, 5617-5622.

Fukui, Y., and Yamamoto, M. (1988) Isolation and characterization of Schizosaccharomyces pombe mutants phenotypically similar to ras1-. Mol. Gen. Genet. 215, 26-31.

Gabriel, M., and Kopecká, M. (1995) Disruption of the actin cytoskeleton in budding yeast results in formation of an aberrant cell wall. Microbiology 141, 891-899.

Garrett-Engele, P., Moilanen, B., and Cyert, M. S. (1995) Calcineurin, the $\mathrm{Ca}^{2+} /$ calmodulin-dependent protein phosphatase, is essential in yeast mutants with cell integrity defects and in mutants that lack a functional vacuolar $\mathrm{H}^{+}$ATPase. Mol. Cell. Biol. 15, 4103-4114.

Gilbreth, M., Yang, P., Wang, D., Frost, J., Polverino, A., Cobb, M. H., and Marcus, S. (1996) The highly conserved skb1 gene encodes a protein that interacts with Shk1, a fission yeast Ste20/PAK homolog. Proc. Natl. Acad. Sci. USA 93, 1380213807.

Godoy, C., Arellano, M., Diaz, M., Duran, A., and Perez, P. (1996) Characterization of $\mathrm{cwl1}^{+}$, a gene from Schizosaccharomyces pombe whose overexpression causes cell lysis. Yeast 12,983990.

Herskowitz, I. (1995) MAP kinase pathways in yeast: For mating and more. Cell 80, 187-197.

Hirata, D., Nakano, K., Fukui, M., Takenaka, H., Miyakawa, T., and Mabuchi, I. (1998) Genes that cause aberrant cell morphology by overexpression in fission yeast: a role of a small GTP-binding protein Rho2 in cell morphogenesis. J. Cell Sci. 111, 149-159.

Horisberger, M., and Rosset, J. (1977) Localization of $\alpha$ galactomannan on the surface of Schizosaccharomyces pombe cells by scanning electron microscopy. Arch. Microbiol. 112, $123-126$.

Horisberger, M., and Rouvet-Vauthey, M. (1985) Cell wall architechture of the fission yeast Schizosaccharomyces pombe. Experientia 41, 748-750.

Horisberger, M., Vonlanthen, M., and Rosset, J. (1978) Localization of $\alpha$-galactomannan and of wheat germ agglutinin receptors in Schizosaccharomyces pombe. Arch. Microbiol. 119, 107-111.

Hughes, D. A., Fukui, Y., and Yamamoto, M. (1990) Homologous activators of ras in fission and budding yeast. Nature 344, $355-357$.

Imai, Y., Miyake, S., Hughes, D. A., and Yamamoto, M. (1991) Identification of a GTPase-activating protein homolog in Schizosaccharomyces pombe. Mol. Cell. Biol. 11, 3088-3094.
Inoue, S. B., Qadota, H., Arisawa, M., Anraku, Y., Watanabe, T.,

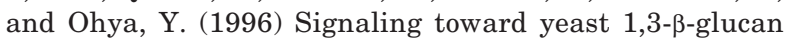
synthesis. Cell Struct. Funct. 21, 395-402.

Inoue, S. B., Takewaki, N., Takasuka, T., Mio, T., Adachi, M., Fujii, Y., Miyamoto, C., Arisawa, M., Furuichi, Y., and Watanabe, T. (1995) Characterization and gene cloning of 1,3- $\beta$-D-glucan synthase from Saccharomyces cerevisiae. Eur. J. Biochem. 231, 845-854.

Ishiguro, J., and Kobayashi, W. (1996) An actin point-mutation neighboring the 'hydrophobic plug' causes defects in the maintenance of cell polarity and septum organization in the fission yeast Schizosaccharomyces pombe. FEBS Lett. 392, 237241.

Ishiguro, J., Saitou, A., Durán, A., and Ribas, J. C. (1997) cps $1^{+}$, a Schizosaccharomyces pombe gene homolog of Saccharomyces cerevisiae FKS genes whose mutation confers hypersensitivity to cyclosporin A and papulacandin B. J. Bacteriol. 179, $7653-7662$.

Kanbe, T., Kobayashi, I., and Tanaka, K. (1989) Dynamics of cytoplasmic organelles in the cell cycle of the fission yeast Schizosaccharomyces pombe: three-dimensional reconstruction from serial sections. J. Cell Sci. 94, 647-656.

Kinoshita, K., Nemoto, T., Nabeshima, K., Kondoh, H., Niwa, H., and Yanagida, M. (1996) The regulatory subunits of fission yeast protein phosphatase 2A (PP2A) affect cell morphogenesis, cell wall synthesis and cytokinesis. Genes Cells 1, 2945 .

Klis, F. M. (1994) Cell wall assembly in yeast. Yeast 10, 851869.

Kobori, H., Yamada, N., Taki, A., and Osumi, M. (1989) Actin is associated with the formation of the cell wall in reverting protoplasts of the fission yeast Schizosaccharomyces pombe. J. Cell Sci. 94, 635-646.

Kobori, H., Toda, T., Yaguchi, H., Toya, M., Yanagida, M., and Osumi, M. (1994) Fission yeast protein kinase C gene homologues are required for protoplast regeneration: a functional link between cell wall formation and cell shape control. J. Cell Sci. 107, 1131-1136.

Levin, D. E., and Bishop, J. M. (1990) A putative protein kinase gene $\left(K i n 1^{+}\right)$is important for growth polarity in Schizosaccharomyces pombe. Proc. Natl. Acad. Sci. USA 87, 8272-8276.

Kreger, D. R., and Kopecká, M. (1978) Nature of the nets produced by protoplasts of Schizosaccharomyces pombe during the first stage of wall regeneration in liquid media. J. Gen. Microbiol. 108, 269-274.

Leupold, U. (1991) Characterization of a partially fertile ras1-like ste10 UGA nonsense mutant of fission yeast. Curr. Genet. 20, $75-78$.

Manners, D. J., Masson, A. J., and Patterson, J. C. (1974) The heterogeneity of glucan preparations from the walls of various yeasts. J. Gen. Microbiol. 80, 411-417.

Manners, D. J., and Meyer, M. T. (1977) The molecular structures of some glucans from the cell walls of Schizosaccharomyces pombe. Carbohydr. Res. 57, 189-203.

Marcus, S., Polverino, A., Chang, E., Robbins, D., Cobb, M. H., and Wigler, M. H. (1995) Shk1, a homolog of the Saccharomyces cerevisiae Ste 20 and mammalian $\mathrm{p} 65^{\mathrm{PAK}}$ protein kinases, is a component of a Ras/Cdc42 signaling module in the fission yeast Schizosaccharomyces pombe. Proc. Natl. Acad. Sci. USA 92, 6180-6184.

Marks, J., Hagan, I. M., and Hyams, J. (1986) Growth polarity and cytokinesis in fission yeast: The role of the cytoskeleton. J. Cell Sci. Suppl. 5, 229-241.

Marks, J., and Hyams, J. S. (1985) Localization of F-actin through the cell division cycle of Schizosaccharomyces pombe. Eur. 
J. Cell Biol. 39, 27-32.

Mata, J., and Nurse, P. (1997) tea1 and the microtubular cytoskeleton are important for generating global spatial order within the fission yeast cell. Cell 89, 939-949.

Matsumoto, T., and Beach D. (1993) Interaction of the pim1/spi1 mitotic checkpoint with a protein phosphatase. Mol. Biol. Cell 4, 337-345.

Matsusaka, T., Hirata, D., Yanagida, M., and Toda, T. (1995) A novel protein kinase gene $s s p 1^{+}$is required for alteration of growth polarity and actin localization in fission yeast. EMBO J. 14, 3325-3338.

Mazur, P., and Baginsky, W. (1996) In vitro activity of 1,3,-- $\beta-\mathrm{D}-$ glucan synthase requires the GTP-binding pritein Rho1. J. Biol. Chem. 271, 14604-14609.

Mazur, P., Morin, N., Baginsky, W., EL-Sherbeini, M., Clemas, J. A., Nielsen, J. B., and Foor, F. (1995) Differential expression and function of two homologous subunits of yeast 1,3- $\beta-\mathrm{D}$ glucan synthase. Mol. Cell. Biol. 15, 5671-5681.

Miller, P. J., and Johnson, D. I. (1994) Cdc42p GTPase is involved in controlling polarized cell growth in Schizosaccharomyces pombe. Mol. Cell. Biol. 14, 1075-1083.

Millar, J. B., Buck, V., and Wilkinson, M. G. (1995) Pyp1 and pyp2 PTPases dephosphorylate an osmosensing MAP kinase controlling cell size at division in fission yeast. Genes Dev. 9, 2117-2130.

Minet, M., Nurse, P., Thuriaux, P., and Mitchison, J. M. (1979) Uncontrolled septation in a cell division cycle mutant of the fission yeast Schizosaccharomyces pombe. J. Bacteriol. 137, 440-446.

Mitchison, J. M., and Nurse, P. (1985) Growth in cell length in the fission yeast Schizosaccharomyces pombe. J. Cell Sci. 75, $357-376$.

Nakano, K., and Mabuchi, I. (1995) Isolation and sequencing of two cDNA colnes encoding Rho proteins from the fission yeast Schizosaccharomyces pombe. Gene 155, 119-122.

Nakano, K., Arai, R., and Mabuchi, I. (1997) The small GTP-binding protein Rho1 is a mulfifunctional protien that regulates actin localization, cell polarity, and septum formation in the fission yeast Schizosaccharomyces pombe. Genes Cells 2, $679-694$.

Novick, P., and Botstein, D. (1985) Phenotypic analysis of temperature-sensitive yeast actin mutants. Cell 40, 405-416.

Nurse, P. (1994) Fission yeast morphogenesis - Posing the problems. Mol. Biol. Cell 5, 613-616.

Nurse, P., Thuriaux, P., and Nasmyth, K. (1976) Genetic control of the cell division cycle in the fission yeast Schizosaccharomyces pombe. Mol. Gen. Genet. 146, 167178.

Orlean, P. (1997) Biogenesis of yeast wall and surface components. In: The Molecular and Cellular Biology of the Yeast Saccharomyces. (eds.: J. R. Pringle, J. R. Broach, and E. W. Jones), pp. 229-362. Cold Spring Horbor Labolatory Press, Cold Spring Harbor, NY.

Osumi, M., Yamada, N., Kobori, H., Taki, A., Naito, N., Baba, M., and Nagatani, T. (1989) Cell wall formation in regenerating protoplasts of Schizosaccharomyces pombe: Study by high resolution, low voltage scanning electron microscopy. J. Electron Microsc. 38, 457-468.

Osumi, M., Yamada, N., Yaguchi, H., Kobori, H., Nagatani, T., and Sato, M. (1995) Ultrahigh-resolution low-voltage SEM reveals ultrastructure of the glucan network formation from fission yeast protoplast. J. Electron Microsc. 44, 198-206.

Ottilie, S., Miller, P. J., Johnson, D. I., Creasy, C. L., Sells, M. A., Bagrodia, S., Forsburg, S. L., and Chernoff, J. (1995) Fission yeast $p a k 1^{+}$encodes a protein kinase that interacts with Cdc42p and is involved in the control of cell polarity and mating. EMBO J. 14, 5908-5919.

Poole R. K., and Lloyd, D. (1973) Effect of 2-deoxy-D-glucose on growth and cell walls of Schizosaccharomyces pombe 972 $\mathrm{h}^{-}$. Arch. Mikrobiol. 88, 257-272.

Qadota, H., Python, C. P., Inoue, S. B., Arisawa, M., Anraku. Y., Zheng, Y., Watanabe, T., Levin, D. E., and Ohya, Y. (1996) Identification of yeast Rho1p GTPase as a regulatory subunit of 1,3- $\beta$-glucan synthase. Science 272, 279-281.

Ram, A. F. J., Brekelmans, S. S. C., Oehlen, L. J. W. M., and Klis, F. M. (1995) Identification of two cell cycle regulated genes affecting the $\beta$-1,3-glucan content of cell walls in Saccharomyces cerevisiae. FEBS Lett. 358, 165-170.

Ribar, B., Banrevi, A., and Sipiczki, M. (1997) sep $1^{+}$encodes a transcription-factor homologue of the HNF-3/forkhead DNA-binding-domain family in Schizosaccharomyces pombe. Gene 202, 1-5.

Ribas, J. C., Diaz, M., Duran, A., and Perez, P. (1991a) Isolation and characterization of Schizosaccharomyces pombe mutants defective in cell wall (1-3) $\beta$-D-glucan. J. Bacteriol. 173, 3456-3462.

Ribas, J. C., Roncero, C., Rico, H., and Durán, A. (1991b) Characterization of a Schizosaccharomyces pombe morphological mutant altered in the galactomannan content. FEMS Microbiol. Lett. 79, 263-268.

Robinow, C. F., and Hyams, J. S. (1989) General cytology of fission yeasts. In: Molecular Biology of the Fission Yeast (eds.: A. Nasim, P. Young, and B. F. Johnson), pp. 273-330. Academic Press, San Diego.

Roussou, I., and Draetta, G. (1994) The Schizosaccharomyces pombe casein kinase II $\alpha$ and $\beta$ subunits: Evolutionary conservation and positive role of the $\beta$ subunit. Mol. Cell. Biol. 14, 576-586.

Samejima, I., Mackie, S., and Fantes, P. A. (1997) Multiple modes of activation of the stress-responsive MAP kinase pathway in fission yeast. EMBO J. 16, 6162-6170.

Sengar, A. S., Markley, N. A., Marini, N. J., and Young, D. (1997) Mkh1, a MEK kinase required for cell wall integrity and proper response to osmotic and temperature stress in Schizosaccharomyces pombe. Mol. Cell. Biol. 17, 3508-3519.

Shimanuki, M., Kinoshita, N., Ohkura, H., Yoshida, T., Toda, T., and Yanagida, M. (1993) Isolation and characterization of the fission yeast protein phosphatase gene $p p e 1^{+}$involved in cell shape control and mitosis. Mol. Biol. Cell 4, 303-313.

Shiozaki, K., Akhavan-Niaki, H., McGowan, C. H., and Russell, P. (1994) Protein phosphatase $2 \mathrm{C}$, endoded by $p t c 1^{+}$, is important in the heat shock response of Schizosaccharomyces pombe. Mol. Cell. Biol. 14, 3742-3751.

Shiozaki, K., and Russell, P. (1995) Counteractive roles of protein phosphatase 2C (PP2C) and a MAP kinase kinase homolog in the osmoregulation of fission yeast. EMBO J. 14, 492-502.

Shiozaki, K., and Russell, P. (1995) Cell-cycle control linked to extracellular environment by MAP kinase pathway in fission yeast. Nature 378, 739-743.

Shiozaki, K., Shiozaki, M., and Russell, P. (1997) Mcs4 mitotic catastrophe suppressor regulates the fission yeast cell cycle through the Wik1-Wis1-Spc1 kinase cascade. Mol. Biol. Cell 8, 409-419.

Sietsma, J. H., and Wessels, J. G. H. (1990) The occurrence of glucosaminoglycan in the wall of Schizosaccharomyces pombe. J. Gen. Microbiol. 136, 2261-2265.

Sipiczki, M., Grallert, B., and Miklos, I. (1993) Mycelial and syncytial growth in Schizosaccharomyces pombe induced by novel septation mutations. J. Cell Sci. 104, 485-493.

Snell, V., and Nurse, P. (1994) Genetic analysis of cell morphogenesis in fission yeast - a role for casein kinase II in the establishment of polarized growth. EMBO J. 13, 2066-2074. 
Song, K., Mach, K. E., Chen, C-Y., Reynolds, T., and Albright, C. F. (1996) A novel suppressor of ras1 in fission yeast, byr4, is a dosage-dependent inhibitor of cytokinesis. J. Cell Biol. 133, 1307-1319.

Su, L-K., Burrell, M., Hill, D. E., Gyuris, J., Brent, R., Wiltshire, R., Trent, J., Vogelstein, B., and Kinzler, K. W. (1995) APC binds to the novel protein EB-1. Cancer Res. 55, 2972-2977.

Sugiura, R., Toda, T., Shuntoh, H., Yanagida, M., and Kuno, T. (1998) $p m p 1^{+}$, a suppressor of calcineurin deficiency, encodes a novel MAP kinase phosphatase in fission yeast. EMBO J. 17, 140-148.

Tanaka, K., Okazaki, K., Okazaki, N., Ueda, T., Sugiyama, A., Nojima, H., and Okayama, H. (1992) A new cdc gene required for S phase entry of Schizosaccharomyces pombe encodes a protein similar to the $c d c 10^{+}$and $S W I 4$ gene products. EMBO J. 11, 4923-4932.

Toda, T., Shimanuki, M., and Yanagida, M. (1991) Fission yeast genes that confer resistance to staurosporine encode an AP-1like transcription factor and a protein kinase related to the mammalian ERE1/MAP2 and budding yeast FUS3 and KSS1 kinases. Gene Dev. 5, 60-73.

Toda, T., Shimanuki, M., and Yanagida, M. (1993) Two novel protein kinase C-related genes of fission yeast are essential for cell viability and implicated in cell shape control. EMBO J. 12, 1987-1995.

Toda, T., Dhut, S., Superti-Furga, G., Gotoh, Y., Nishida, E., Sugiura, R., and Kuno, T. (1996a) The fission yeast $p m k 1^{+}$ gene encodes a novel mitogen-activated protein kinase homolog which regulates cell integrity and functions coordi- nately with the protein kinase C pathway. Mol. Cell. Biol. 16, 6752-6764.

Toda, T., Niwa, H., Nemoto, T., Dhut, S., Eddison, M., Matsusaka, T., Yanagida, M., and Hirata, D. (1996 b) The fission yeast $s t s 5^{+}$gene is required for maintenance of growth polarity and functionally interacts with protein kinase $\mathrm{C}$ and an osmosensing MAP-kinase pathway. J. Cell Sci. 109, 2331-2342.

Tu, H., Barr, M., Dong, D. L., and Wigler, M. (1997) Multiple regulatory domains on the Byr2 protein kinase. Mol. Cell. Biol. 17, 5876-5887.

Verde, F., Mata, J., and Nurse, P. (1995) Fission yeast cell morphogenesis: Identification of new genes and analysis of their role during the cell cycle. J. Cell Biol. 131, 1529-1538.

Yoshida, T., Toda, T., and Yanagida, M. (1994) A calcineurin-like gene $p p b 1^{+}$in fission yeast: mutant defects in cytokinesis, cell polarity, mating and spindle pole body positioning. J. Cell Sci. 107, 1725-1735.

Zaitsevskaya-Carter, T., and Cooper, J. A. (1997) Spm1, a stressactivated MAP kinase that regulates morphogenesis in $S$. pombe. EMBO J. 16, 1318-1331.

Zhao, C., Jung, U. S., Garrett-Engele, P., Roe, T., Cyert, M. S., and Levin, D. E. (1998) Temperature-induced expression of yeast FKS2 is under the dual control of protein kinase $\mathrm{C}$ and calcineurin. Mol. Cell. Biol. 18, 1013-1022.

Ziman, M., O'Brien, J. M., Ouellette, L. A., Church, W. R., and Johnson, D. I. (1991) Mutational analysis of CDC42Sc, a Saccharomyces cerevisiae gene that encodes a putative GTP-binding protein involved in the control of cell polarity. Mol. Cell. Biol. 11, 3537-3544. 